\title{
Non-linear behavior of root and stem diameter changes in monopodial orchid
}

\author{
Mohd Khairi Nordin', Mohammad Farid Saaid², Nooritawati Md Tahir ${ }^{3}$, Ahmad Ihsan Mohd Yassin ${ }^{4}$, \\ Megat Syahirul Amin Megat Ali ${ }^{5}$ \\ ${ }^{1,2,3}$ School of Electrical Engineering, College of Engineering, Universiti Teknologi MARA, Shah Alam, Malaysia \\ ${ }^{4,5}$ Microwave Research Institute, Universiti Teknologi MARA, Shah Alam, Malaysia
}

\begin{tabular}{l} 
Article Info \\
\hline Article history: \\
Received Jul 14, 2021 \\
Revised Sep 29, 2021 \\
Accepted Oct 15, 2021 \\
\hline
\end{tabular}

\section{Keywords:}

Linearity test

Orchid

Root diameter

Smart farming

Stem diameter

\begin{abstract}
Precision agriculture aims to maximize yield with optimum resources. Vast majority of natural systems are acknowledged as complex and non-linear. However, prior to formulation of precise models, linearity tests are performed to validate plant behavior. This study has presented proof that the water uptake system in monopodial orchid is indeed non-linear. The change in physical growth of root and stem due to temperature and relative humidity factors are observed. The work focused on Ascocenda Fuchs Harvest Moon x (V. Chaophraya x Boots) orchid hybrid. Three complementary methods are presented: linearity tests through 1) regression fitting; 2) scatter plots; and 3) cross-correlation function tests. Root diameter, stem diameter, temperature, and relative humidity are logged at 15 minutes interval for a duration of 71 days. The polynomial equations derived for root diameter and stem diameter changes attained strong regression coefficients. The non-linear behavior is further confirmed by the scatter plots where no linear associations are present between the independent and dependent variables. Subsequently, the crosscorrelation function tests conducted on temperature-root diameter, temperature-stem diameter, relative humidity-root diameter, and relative humidity-stem diameter combinations also revealed weak correlation. Despite using different techniques, the behavior of physical changes has been consistently proven to be non-linear.
\end{abstract}

This is an open access article under the CC BY-SA license.

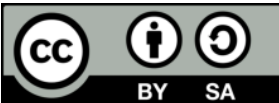

\section{Corresponding Author:}

Megat Syahirul Amin Megat Ali

Microwave Research Institute

Universiti Teknologi MARA

40450 Shah Alam, Selangor, Malaysia

Email: megatsyahirul@uitm.edu.my

\section{INTRODUCTION}

In natural systems, elements, boundary, and relationships exist independently of human control. These can be observed from the growth behavior in plants that is influenced by environmental factors such as water, temperature, humidity, and nutrients [1]-[3]. Natural systems are acknowledged as being complex and non-linear [4]-[6]. In precision agriculture, also widely known as smart farming; growth quality, disease management, farm resources management, and yield has been extensively studied [7]-[11]. These have led to sustainable crop yield [12] which then contribute to the economic growth of the society [10], [13]-[15]. Water is a fundamental element [16] that is required by all living organisms. Studies have shown that $20 \%$ of global usage of water is allocated for agriculture activities [17] and in some countries, the percentage keeps on increasing [18]. Therefore, such resource must be managed efficiently. Water status is an important indicator for assessing stress and growth of plant as it provides the best level of sensitivity [19], [20]. 
To efficiently monitor and control resources, its water consumption characteristics will need to be studied [21]. The aim is to determine optimum requirement for obtaining the best yield. Several studies have been conducted in the past, each utilizing unique approach for measuring different parts of the plant. These include assessing physical information from the roots, leaves, stems, and fruits [22]. Meanwhile, soil moisture is consistently related to the water status in plants.

Such studies, however, are to be limited to terrestrial plants, and not epiphytes. The epiphytes, also known as orchids, has generated considerable amount of revenue to countries such as Malaysia. Epiphytes have been included in the national conservation policies since 1992 and continues through 2020. This study presents an analysis on root and stem growth data from the monopodial orchid, Ascocenda Fuchs Harvest Moon x (V. Chaophraya x Boots). The study focuses on the inter-dependence between the measured growth in root and stem diameter, in response to temperature, and relative humidity. Generally, the water movement theory has outlined that both independent variables are positively associated with water retention in plants and thus, increased diameter in root and stem.

Three complementary methods are proposed to confirm the non-linearity of its behavior: 1) mathematical proof through polynomial regression; 2) dependence test via scatter plots; and 3) correlation tests. The findings serve as a fundamental validation of data in the development of non-linear growth model for epiphytes. The rest of this paper is organized in the following sequence. Section 2 described the theoretical background of the proving methods. This is then followed by research methods in section 3 . Subsequently, section 4 presents the results and discussion. Lastly, the concluding remarks is summarized in section 5.

\section{THEORETICAL BACKGROUND}

\subsection{Linearity test}

A system is best represented by a model corresponding to its linearity behavior. Therefore, it is important to ascertain its nature prior to selecting a system identification model. Generally, linear systems must comply with the superposition principle where the net response caused by two or more inputs is the sum of responses that would have been elicited by the individual input components. These are mathematically expressed by additivity and homogeneity properties shown by (1), where $x_{1}(n)$ and $x_{2}(n)$ each represents inputs, $a_{1}$ and $a_{2}$ are constants, and $\mathrm{T}$ is the transformation function.

$$
\mathrm{T}\left[a_{1} x_{1}(n)+a_{2} x_{2}(n)\right]=\mathrm{T}\left[a_{1} x_{1}(n)\right]+\mathrm{T}\left[a_{2} x_{2}(n)\right]
$$

If the net response caused by two or more inputs is not proportional to the sum of responses elicited by the individual input components, then the system is considered as non-linear [23].

\subsection{Scatter plot}

Inter-dependency between two variables can be illustrated using scatter plots. The method is commonly used to show trends, patterns, and relationships for large and multivariate data [24], [25]. The method is implemented prior to performing tests that quantifies the relationship between variables. Scatter plots is drawn by mapping the locations on a two-dimensional cartesian mapping system. The $x$-axis is the independent variable, and the $y$-axis is the dependent variable. Both variables are measured on fixed intervals.

\subsection{Correlation}

The degree of inter-dependence between two variables can be evaluated using correlation test. The method uses coefficients to measure the strength of linear association between these variables [26]. The value of coefficients range between -1 which to 1 [27]. A coefficient of -1 indicates negative correlation, while a value of 1 indicates positive relationship between the independent and dependent variables. If both variables are not correlated, the coefficient is 0 . The correlation coefficient, $r_{x y}$, between independent variable $x$, and dependent variable, $y$, is shown by (2).

$$
r_{x y}=\frac{\sum\left(x_{i}-\bar{x}\right)\left(y_{i}-\bar{y}\right)}{\sqrt{\sum\left(x_{i}-\bar{x}\right)^{2} \sum\left(y_{i}-\bar{y}\right)^{2}}}
$$

Note that Pearson correlation is only sensitive to linear correlation validation as compared to Spearman and Kendall correlation. The two later methods are more suitable for non-linear correlation studies. 


\section{RESEARCH METHOD}

\subsection{Data collection}

The water uptake model in orchids is illustrated in Figure 1. Temperature and relative humidity are the independent variables. Meanwhile, the change in root and stem diameter are the dependent variables.

Measurements for Ascocenda Fuchs Harvest Moon x (V. Chaophraya x Boots) is recorded from $4^{\text {th }}$ April 2020 to $20^{\text {th }}$ June 2020. As shown in Figure 2, two Ecomatik dendrometers are attached to the roots and the other two to the stem of the orchid plant. Note that stem 1 sensor is placed at the active growth zone of the orchid. Meanwhile, stem 2 sensor is placed close to the root, and root 1 sensor is near to the base of the stem. Root 2 sensor is placed further down the root.

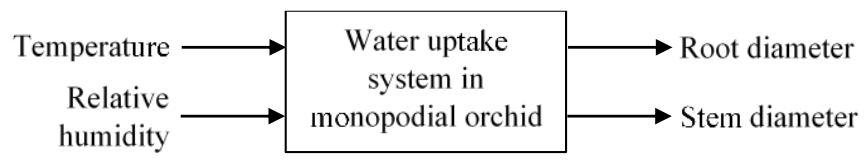

Figure 1. System input-output

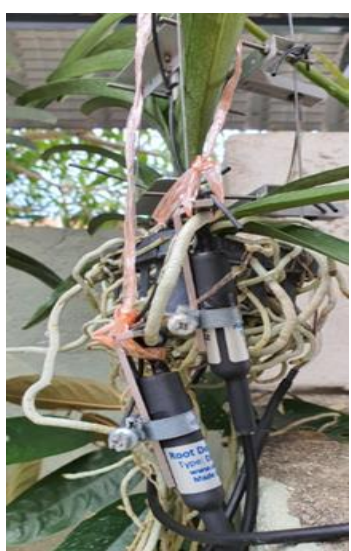

(a)

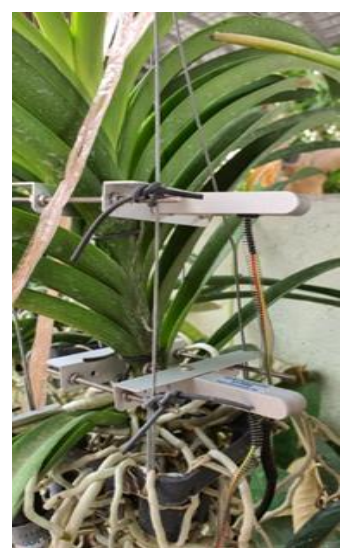

(b)

Figure 2. Displacement sensor for, (a) root, (b) stem measurements

Measurements from temperature, relative humidity and dendrometer sensors are logged at 15 minutes interval using HOBO data logger. From $11^{\text {th }}$ April 2020 to $3^{\text {rd }}$ June 2020, the orchid is watered twice daily and placed under rain protective area with $75 \%$ to $85 \%$ sunlight during daytime. The roots of vandaceous orchid are not implanted in any form of media but exposed to the surroundings. Therefore, the plant captures water from being supplied directly and humid air through its intricate root network. From $4^{\text {th }}$ June 2020 onwards, watering of the orchid is halted to elicit water stress condition.

\subsection{Linearity tests using regression fitting and scatter plot}

The main aim of this experiment is to prove whether the water uptake system to be modelled is indeed non-linear. After data collection has been completed, the time-series information is then plotted to observe parameter variations with time. Then, equations that best fits the behavior of root and stem changes are derived. Subsequently, these are tested using regression fitting. To further confirm this, scatter plots are also used to demonstrate the relationship between the dependent variables with each of the independent variables.

\subsection{Cross-correlation function tests}

To conclude earlier observations from regression analysis and scatter plots, the study also implements cross-correlation function tests. Generally, cross-correlation is a measure of similarity of two series as a function of the displacement of one relative to the other. The sample cross-correlation is defined as the set of sample correlations between $x(n+k)$ and $y(n)$ for $k= \pm 1, \pm 2, \pm 3$ and so on. A negative value for $k$ is a correlation between $x$ at a time before $n$ and $y$ at time $n$. For both dependent and independent to be correlated, the coefficients at all lags must fall within the $95 \%$ confidence interval. The intervals, $\Delta$, are influenced by the number of samples, $N$, in the dataset. The relationship between both parameters is expressed by (3). 


$$
\Delta= \pm \frac{1.96}{\sqrt{N}}
$$

Should the coefficient values be less than \pm 0.3 , however, the correlation is considered weak, and the system still exhibits a high degree of non-linearity.

\section{RESULTS AND DISCUSSION}

\subsection{Linearity tests using regression fitting and stem plot}

The root and stem diameter changes over time is shown in Figure 3. The smaller daily fluctuations can be observed from the root and stem diameter data. Stem 1 sensor is placed at the active growth zone of the orchid. Meanwhile, stem 2 sensor is placed close to the root, and root 1 sensor is near to the base of the stem. Root 2 sensor is placed further down the towards the root. The varying sensor distances allow observation of water stress at different parts of the plant.

From $11^{\text {th }}$ April 2020 to $3^{\text {rd }}$ June 2020, the orchid is watered twice daily using mist spraying method. However, the reduction in diameters for root 1 , root 2 , and stem 2 indicate that the watering practice is inadequate. This initiated the water stress response. The diameter change is most severe at root 2 . From the results, water is transported by the root network and stem towards the active growth zone, resulting in increased diameter at stem 1. From $4^{\text {th }}$ June 2020 onwards, water stress is not only observable at root 1, root 2, and stem 2, but also stem 1 . The best-fitting polynomial curves for different degrees were estimated and their fit to the original data are presented in Table 1. The estimated curves appear to be in good agreement with the original data, exhibiting $\mathrm{R}^{2}$ above 0.8 .

1000

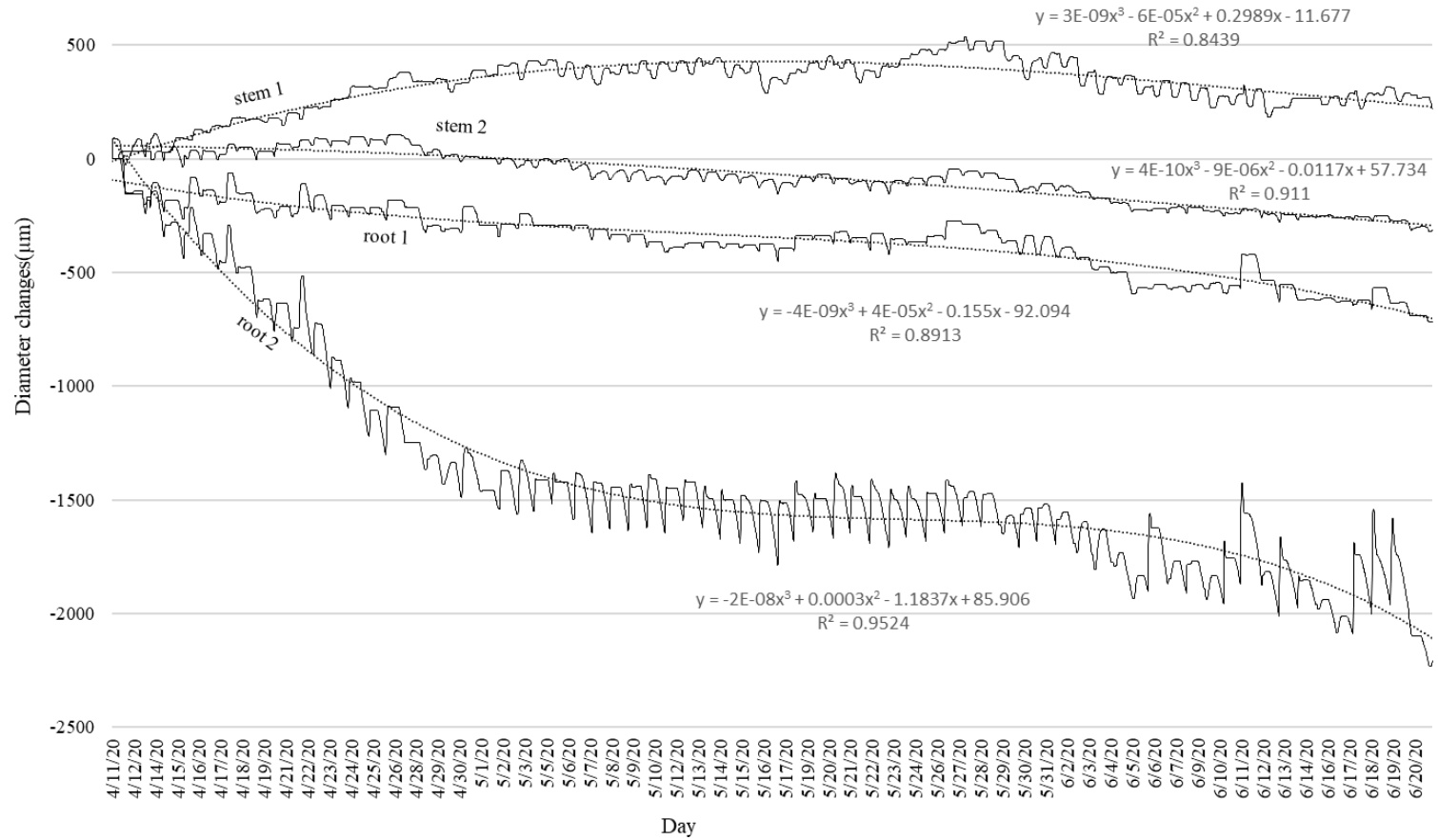

Figure 3. Root and stem response with time

Table 1. Regression coefficient and different polynomials

\begin{tabular}{ccccc}
\hline Polynomial & \multicolumn{4}{c}{$\mathrm{R}^{2}$} \\
\cline { 2 - 5 } & Root 1 & Root 2 & Stem 1 & Stem 2 \\
\hline 2 & 0.8642 & 0.8712 & 0.8513 & 0.9105 \\
3 & 0.8913 & 0.9524 & 0.8439 & 0.9110 \\
4 & 0.8914 & 0.9552 & 0.8443 & 0.9202 \\
5 & 0.9043 & 0.9663 & 0.8657 & 0.9396 \\
6 & 0.9043 & 0.9663 & 0.8899 & 0.9430 \\
\hline
\end{tabular}


Despite the improvements in regression value for $6^{\text {th }}$-order polynomial, the $3^{\text {rd }}$-order equations appear to be the best at generalizing the trend line. The derived equation already revealed its non-linearity. To test the superposition principle, the polynomial which describes the behavior of root 2 is assumed to take the form of (4) and (5).

$$
\begin{aligned}
& y_{1}=\left(-2 \times 10^{-8}\right) x_{1}^{3}+0.003 x_{1}^{2}-1.1837 x_{1}-85.906 \\
& y_{2}=\left(-2 \times 10^{-8}\right) x_{2}^{3}+0.003 x_{2}^{2}-1.1837 x_{2}-85.906
\end{aligned}
$$

In (6) is then obtained by summing up the two preceding equations.

$$
\begin{aligned}
& y_{3}=\left(-2 \times 10^{-8}\right)\left(x_{1}^{3}+x_{2}^{3}\right)+0.003\left(x_{1}^{2}+x_{2}^{2}\right)-1.1837\left(x_{1}+x_{2}\right)-171.812 \\
& y_{4}=\left(-2 \times 10^{-8}\right)\left(x_{1}+x_{2}\right)^{3}+0.003\left(x_{1}+x_{2}\right)^{2}-1.1837\left(x_{1}+x_{2}\right)-85.906
\end{aligned}
$$

From the derived equations, the output $y_{3}$ do not yield the same expression as $y_{4}$. Therefore, the superposition principle is not followed, and the system is non-linear. The dependent variables can also be mapped to the independent variables through scatter plots. From this point, only results for root 1 and Stem 2 is used as examples. Figure 4 shows the effects of temperature on the root and stem diameter changes in orchid.

Based on the visual observation, there were no discernable pattern present in both plots, suggesting that there are strong non-linear associations between both variables. Meanwhile, the scatter plots for relative humidity against root and stem diameter change are shown in Figure 5. Similarly with the influence of temperature on the root diameter change in the orchid plant, no distinct pattern has been observed in both scatter plots. These also imply a strong non-linear relationship between relative humidity with root and stem diameter changes.

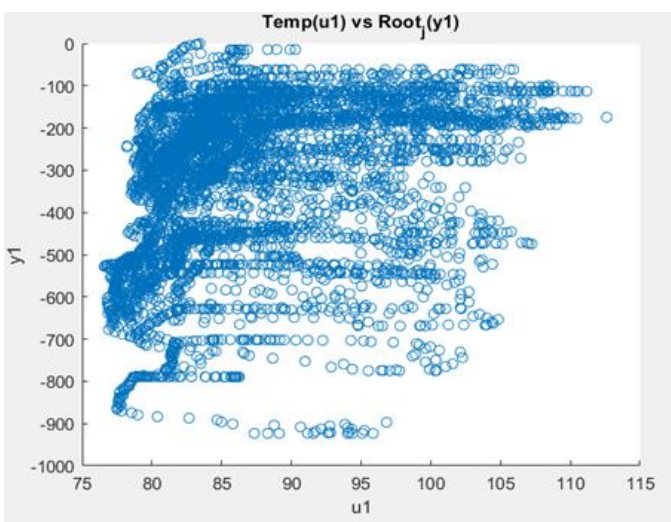

(a)

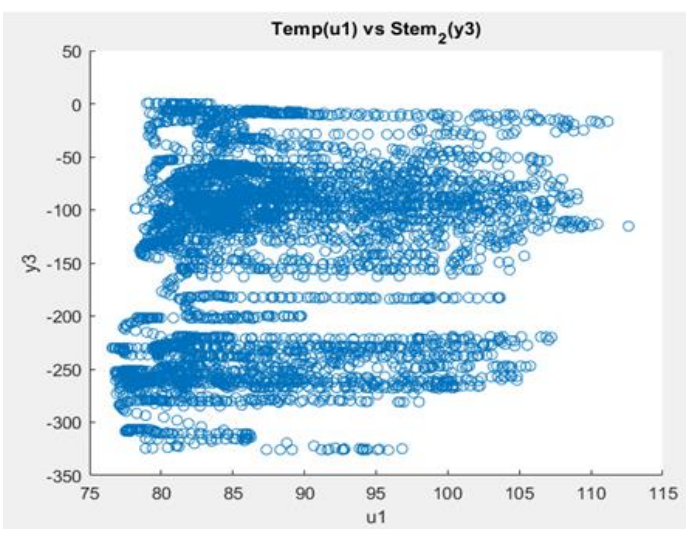

(b)

Figure 4. Scatter plots for; (a) temperature vs root diameter change, (b) temperature vs stem diameter change

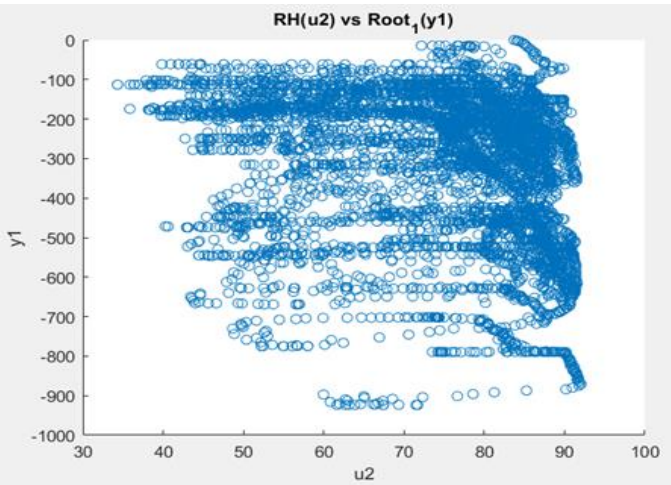

(a)

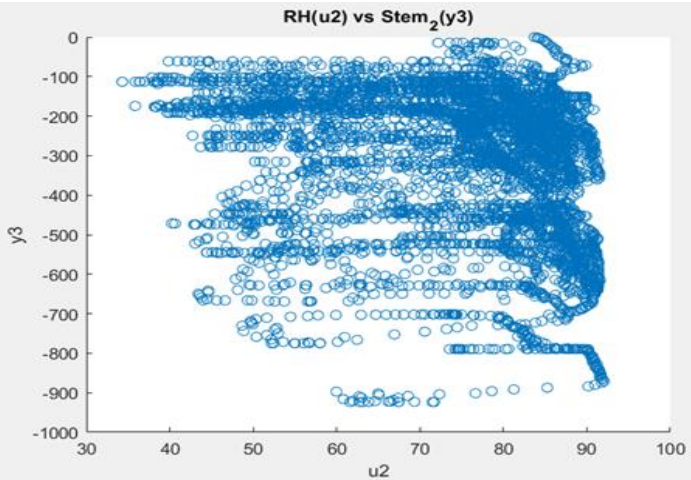

(b)

Figure 5. Scatter plots for; (a) relative humidity vs root diameter change, (b) relative humidity vs stem diameter change 


\subsection{Cross-correlation function tests}

Thus far, data on the water uptake system has demonstrated non-linear behavior. For further confirmation, the relationship between the studied variables is examined through the cross-correlation function tests. Figure 6 shows the cross-correlation between temperature and the physical changes of the orchid plant. Based on the sample cross-correlation plots, the root and stem diameter changes are positively associated with temperature as the coefficients consistently exceeded $95 \%$ confidence interval for all lags. These suggest that water retention is higher in both root and stem with increased temperature.

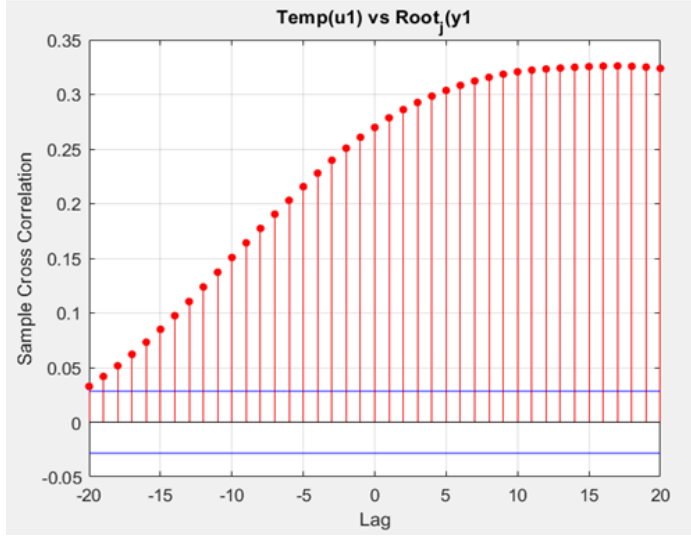

(a)

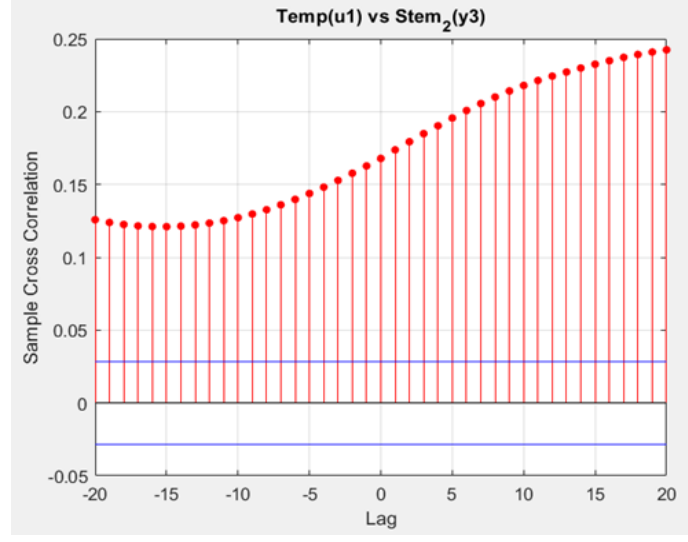

(b)

Figure 6. Cross-correlation function test between temperature and; (a) root diameter change, (b) stem diameter change

The cross-correlation plot has also revealed the pattern of water uptake system behavior at different lags. Albeit insignificant, the correlation increases from lag -20 to lag 20. This indicates that changes to root and stem diameters in response to temperature is not immediate but delayed. The change in diameter is picked up at the root first, followed by the stem. The delay reflects the processes involved absorption and transportation of water.

Meanwhile, Figure 7 shows the correlation between relative humidity and the diameter changes in root and stem. The sample cross-correlation plots revealed that the root and stem diameter changes are negatively correlated with relative humidity as the coefficients are outside of the $95 \%$ confidence interval for majority of the lags. These suggest that the plant retains less moisture even though the surrounding relative humidity is high. Such findings contradict the transpiration theory which states that water retention is proportional to relative humidity. However, by re-considering the experimental setup and the selected orchid genus, it appears that such behavior is attributed to the nature of the plant that needs to be watered more frequently. Therefore, the stress condition is observed despite the adopted watering practices.

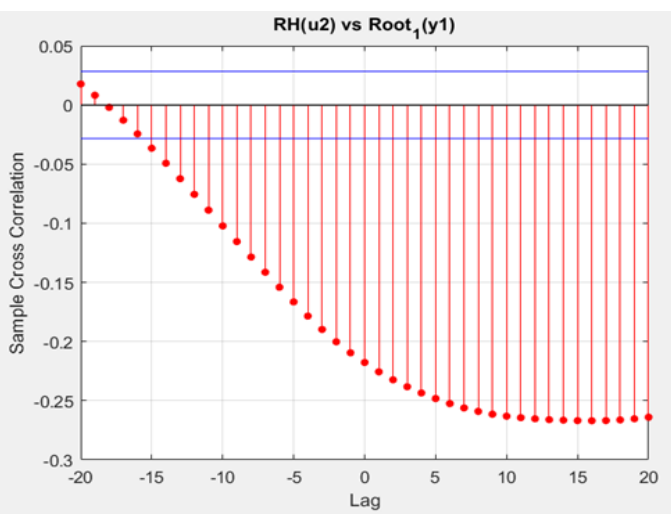

(a)

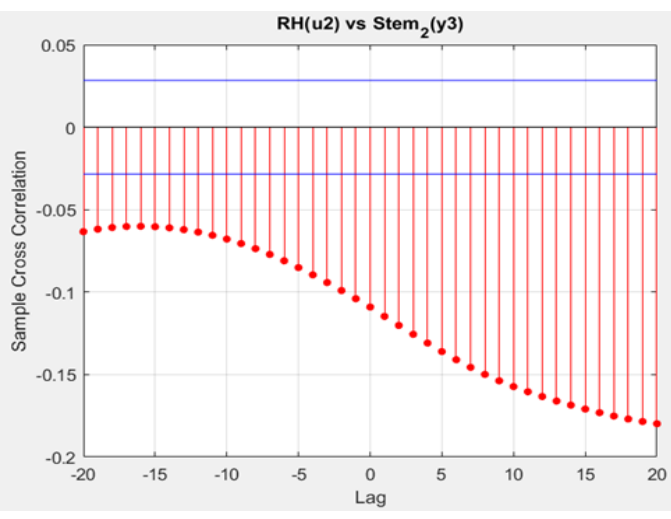

(b)

Figure 7. Cross-correlation function test between relative humidity and, (a) root diameter change, (b) stem diameter change 
The sample cross-correlation also shows the pattern of water uptake system behavior at different lags. Although minute, the correlation increases from lag -20 to lag 20. Similarly with temperature, the root and stem diameters changes are not immediate but delayed. The change is observed at the root first, followed by the stem. The delay reflects water stress in the orchid plant. Despite the relationship shown between the independent variables and the physical changes, the coefficients revealed weak correlations. As illustrated in Table 2, the coefficients at lag 0 for all input-output combinations are within the range of -0.3 and 0.3 .

\begin{tabular}{cc} 
Table 2. Correlation coefficient at lag 0 \\
\hline Input-output combination & Coefficient \\
\hline Temperature-root diameter & 0.267 \\
Temperature-stem diameter & 0.169 \\
Relative humidity-root diameter & -0.218 \\
Relative humidity-stem diameter & -0.109 \\
\hline
\end{tabular}

\section{CONCLUSION}

The study has investigated the behavior of root and stem diameter in monopodial orchid in response to changes in temperature and relative humidity. Measurements were made using experimental setup that is suitable for the exposed root network of vandaceous orchid. To prove that the water uptake system is indeed non-linear, three methods of linearity tests have been proposed: 1) regression fitting; 2) scatter plots, and 3) cross-correlation function tests. Based on the obtained data, polynomial equations derived for root diameter and stem diameter changes have shown strong regression fitting. The non-linear behavior is further confirmed by the scatter plots where no linear associations are present between the independent and dependent variables. Subsequently, the cross-correlation function tests conducted on temperature-root diameter, temperature-stem diameter, relative humidity-root diameter, and relative humidity-stem diameter combinations suggest that the data is non-linear and correlated with each other. There are limitations to the measurement setup of this study. Despite being watered twice daily using mist spray, the plant continuous to demonstrate characteristics of water stress. The only exception is the active growth zone further up the stem. In future experiments involving vandaceous orchid species, it is recommended that the watering be increased so that the physical change behavior can be characterized accurately. Generally, the results presented in this study would assist in guiding the selection of system identification model that can accurately represent the behavior. Specifically, the water uptake model in monopodial orchid is better suited for non-linear structures as it accurately represents of the system being studied. In the future, similar observations can also be extended to sympodial orchid species.

\section{ACKNOWLEDGEMENTS}

This study is financially supported by Universiti Teknologi MARA through the MyRA Research Grant (600-RMC/MyRA 5/3/LESTARI (099/2020)).

\section{REFERENCES}

[1] C. P. Beyer, I. F. Cuneo, J. E. Alvaro and R. Pedreschi, "Evaluation of aerial and root plant growth behavior, water and nutrient use efficiency and carbohydrate dynamics for Hass avocado grown in a soilless and protected growing system," Scientia Horticulturae, vol. 277, p. 109830, February 2021, doi: 10.1016/j.scienta.2020.109830.

[2] R. Paradiso and S. Proietti, "Light-quality manipulation to control plant growth and photomorphogenesis in greenhouse horticulture: The state of the art and the opportunities of modern LED systems," Journal of Plant Growth Regulation, 2021, pp. 1-39, doi: 10.1007/s00344-021-10337-y.

[3] S. I. Zandalinas, F. B. Fritschi and R. Mittler, "Global warming, climate change, and environmental pollution: Recipe for a multifactorial stress combination disaster," Trends in Plant Science, vol. 26, no.6, pp. 588-599, June 2021, doi: 10.1016/j.tplants.2021.02.011.

[4] G. Nicolis, "Introduction to Nonlinear Science," Cambridge University Press, 1995, pp. 1-24.

[5] C. Willy, E. Neugebauer and Gerngroß, "The concept of nonlinearity in complex systems," European Journal of Trauma, vol. 29, pp. 11-22, 2003, doi: 10.1007/s00068-003-1248-x.

[6] C. G. Curtin and T. F. H. Allen, "Non-linearity in Natural, Physical and Social Systems," in Complex Ecology: Foundational Perspectives on Dynamic Approaches to Ecology and Conservation, Eds., Cambridge, UK, 2018, pp. 283-387, doi: 10.1017/9781108235754.006.

[7] U. Shafi, R. Mumtaz, J. Garcia-Nieto, S. A. Hassan, S. A. R. Zaidi and N. Iqbal, "Precision agriculture techniques and practices: From considerations to applications," Sensors, vol. 19, no. 17, p. 3796, September 2019, doi: $10.3390 / \mathrm{s} 19173796$. 
[8] S. M. Say, M. Keskin, M. Sehri and Y. E. Sekerli, "Adoption of precision agriculture technologies in developed and developing countries," The Online Journal of Science and Technology, vol. 8, no. 1, pp. 7-15, January 2018.

[9] V. Saiz-Rubio and F. Rovira-Más, "From smart farming towards Agriculture 5.0: A review on crop data management," Agronomy, vol. 10, no. 2, pp. 1-21, February 2020, doi: 10.3390/agronomy 10020207.

[10] E. Navarro, N. Costa and A. Pereira, "A systematic review of IoT solutions for smart farming," Sensors, vol. 20, no. 15, p. 4231, July 2020, doi: 10.3390/s20154231.

[11] R. Murugesan et al., "Artificial intelligence and Agriculture 5.0," International Journal of Recent Technology and Engineering, vol. 8, no. 8, pp. 1870-1877, July 2019, doi: 10.35940/ijrte. B1510.078219.

[12] N. Zainal, N. Mohamood, M. F. Norman and D. Sanmutham, "Design and implementation of smart farming system for fig using connected-argonomics," International Journal of Electrical and Computer Engineering (IJECE), vol. 9, no. 6, pp. 5653-5662, December 2019, doi: 10.11591/ijece.v9i6.pp5653-5662.

[13] N. I. Tchernyshev, O. E. Sysoev, D. B. Solovev and E. P. Kiselyov, "Basic robotecnical platform for implementation of accurate farming technologies," Bulletin of Electrical Engineering and Informatics (BEEI), vol. 7, no.4, pp. 522-528, December 2018, doi: 10.11591/eei.v7i4.920.

[14] F. N. Shuhaimi, N. Jamil and R. Hamzah, "Evaluations of Internet of Things-based personal smart farming system for residential apartments," Bulletin of Electrical Engineering and Informatics (BEEI), vol. 9, no. 6, pp. 2477-2483, December 2020, doi: 10.11591/eei.v9i6.2496.

[15] R. Lakshmanan, M. Djama, S. K. Selvaperumal and R. Abdulla, "Automated smart hydroponics system using Internet of Things," International Journal of Electrical and Computer Engineering (IJECE), vol. 10, no. 6, pp. 6389-6398, December 2020, doi: 10.11591/ijece.v10i6.pp6389-6398.

[16] J. E. Fernández, F. Alcon, A. Diaz-Espejo, V. Hernandez-Santana and M. V. Cuevasa, "Water use indicators and economic analysis for on-farm irrigation decision: A case study of a super high density olive tree orchard," Agricultural Water Management, vol. 237, p. 106074, July 2020, doi: 10.1016/j.agwat.2020.106074.

[17] W. Qu, Y. Tan, Z. Li, E. Aarnoudse and Q. Tu, "Agricultural water use efficiency-A case study of inland-river basins in Northwest China," Sustainability, vol. 12, no. 23, p. 10192, December 2020, doi: 10.3390/su122310192.

[18] A. Holzkämper, "Varietal adaptations matter for agricultural water use-a simulation study on grain maize in Western Switzerland," Agricultural Water Management, vol. 237, p. 106202, July 2020, doi: 10.1016/j.agwat.2020.106202.

[19] R. Skelton, "Of storage and stems: Examining the role of stem water storage in plant water balance," Plant Physiology, vol. 179, no. 4, pp. 1433-1434, April 2019, doi: 10.1104/pp.19.00057.

[20] Y. Tian, Q. Zhang, X. Liu, M. Meng and B. Wang, "The relationship between stem diameter shrinkage and tree bole moisture loss due to transpiration," Forests, vol. 10, no. 3, p. 290, March 2019, doi: 10.3390/f10030290.

[21] Yun-peng Nie, Hong-song Chen, Ke-lin Wang, W. Tan, Peng-yan Deng and J. Yang, "Seasonal water use patterns of woody species on the continuous dolostone outcrops and nearby thin soils in subtropical China," Plant and Soil, vol. 341, no. 1, pp. 399-412, November 2010, doi: 10.1007/s11104-010-0653-2.

[22] V. Parkash and S. Singh, "A review on potential plant-based water stress indicators for vegetable crops," Sustainability, vol. 12, no. 10, p. 3945, May 2020, doi: 10.3390/su12103945.

[23] S. Saat, S. K. Nguang and A. Nasiri, "Chapter 1-Introduction," in Analysis and Synthesis of Polynomial DiscreteTime Systems, Eds., Oxford, UK: Butterworth-Heinemann, 2017, pp. 1-27.

[24] Q. V. Nguyen, N. Miller, D. Arness, W. Huang, M. L. Huang and S. Simoffa, "Evaluation on interactive visualization data with scatterplots," Visual Informatics, vol. 4, no. 4, pp. 1-10, December 2020, doi: 10.1016/j.visinf.2020.09.004

[25] M. Sedlmair, T. Munzner and M. Tory, "Empirical Guidance on Scatterplot and Dimension Reduction Technique Choices," in IEEE Transactions on Visualization and Computer Graphics, vol. 19, no. 12, pp. 2634-2643, December 2013, doi: 10.1109/TVCG.2013.153.

[26] J. Hauke and T. Kossowski, "Comparison of values of Pearson's and Spearman's correlation coefficients on the same sets of data," Quaestiones Geographicae, vol. 30, no. 2, pp. 87-93, 2011.

[27] S. Senthilnathan, "Usefulness of correlation analysis," SSRN Electronic Journal, pp. 1-9, 2019, doi: $10.2139 /$ ssrn.3416918. 